\title{
L'ESTABLIMENT DE L'ORDE DEL TEMPLE A LA TORTOSA DE SÍRIA (SEGLE XII) ${ }^{1}$
}

\author{
JOSEP S SERRANO DAURA \\ Universitat Internacional de Catalunya
}

\section{SUMARI}

I. El Comtat llatí de Trípoli i la ciutat siriana de Tortosa.- II. El bisbat sirià de Tortosa.- III. La cúria del Comte de Trípoli.- IV. La concòrdia entre el Bisbat sirià de Tortosa i l'Orde del Temple.- Apèndix.

Amb aquest article presentem una concòrdia entre el Bisbat de Tortosa a Síria i l'Orde del Temple per a la construcció a la ciutat d'un nou castell o fortificació a càrrec dels cavallers templers. Aquests pactes de mitjan s. XII suposen l'establiment de l'Orde en aquella ciutat del Comtat tolosà de Trípoli que depèn eclesiàsticament del Patriarcat d'Antioquia.

El document en sí ens permet conèixer quelcom més de l'expansió de l'Orde del Temple pels dominis llatins de l'antic Imperi bizantí (territori on precisament va sorgir); i al mateix temps ens ofereix alguns detalls d'una ciutat oriental germana, per atzar o no, de la Tortosa catalana.

\footnotetext{
'Aquest treball s'inscriu dins el projecte d'investigació titulat "Historia de una institución jurídica: la monarquía en la Corona de Aragón", finançat pel Ministeri d'Educació i Cultura (Ref. PB96-0284) i sota la direcció del Dr. Tomàs de Montagut Estragués (anys 1997-2000). El meu agraïment a la Dra. Ana $\mathrm{M}^{\mathrm{a}}$ Barrero García, de la Universitat Autònoma de Madrid, que molt gentilment va corregir la transcripció del document que publiquem com a Apèndix.
} 
Ambdues ciutats tenen elements històrics comuns: s'erigeixen en Seus de Bisbats i en elles s'instal-len els cavallers templers. No dubtem que per mitjà del Temple s'hi havien d'establir vinculs importants, més tenint en compte que l'Orde, que ja hi té algunes possessions, acaba senyorejant la Tortosa catalana (1182); aquest article pot en definitiva servir per a aproparles històricament.

A més acreditem la presència en aquelles terres de cavallers catalans, vinculats a la Casa Comtal de Barcelona (de Cabrera i Castellnou).

Ja pel que fa al document que publiquem, ens ha arribat per mitjà d'un trasllat defectuós del s. XVI fet formalment sobre altre de 1156; s'ha de dir que no està en gaire bon estat.

\section{El COMTAT LLATÍ DE TRÍPOLI I LA CIUTAT SIRIANA DE TORTOSA}

L'any 1095 el papa Urbà II predica la primera Croada occidental al Concili de Clermont (França), per a recuperar Jerusalem i els llocs de Terra Santa que han estat ocupats pels musulmans ${ }^{2}$.

Entre els cavallers cristians d'Occident que hi participen estan els comtes Guillem II de Cerdanya i el seu oncle Ramon IV de Sant Gelí comte de Tolosa (de Llenguadoc). El 1096 es troben a Constantinoble, i des d'allí inicien el camí cap a Jerusalem ${ }^{3}$.

Abans d'arribar a aquella ciutat i després de passar per Antioquia, els croats conquereixen altres viles i ciutats que són en poder dels musulmans. Una d'elles, l'any 1101 és l'antiga Constantina romana a la que una vegada ocupada les forces croades canvien el nom pel de Tortosa (la Tartoûs o Tartu's àrab) ${ }^{4}$.

\footnotetext{
${ }^{2}$ Ermelindo PorTela, La expansión de Occidente: el Mediterráneo Oriental. Las Primeras Cruzadas, "Historia de la Edad Media", Barcelona, 1992, pp. 185-187.

${ }^{3}$ Ramon de Tolosa arriba a Constantinoble a finals de 1096 amb altres senyors feudals de l'Europa Occidental com: el duc de Lorena, Godofred de Bouillón, Hug de Vermandois, Robert de Normandia, i el príncep normand Bohemund (G. OSTROGORSKY, Historia del Estado Bizantino, Madrid, 1963, p. 357).

${ }^{4} \mathrm{AAVV}$, Recueil des historiens des Gaules et de la France, XIX, París, 1880, pp. 148-149. E. PORTELA, ob. cit., p. 189.
} 
I quasi d'immediat els mateixos croats prenen l'altra ciutat de Trípoli (aleshores de Síria i avui del Líban). Ja aquesta ciutat s'erigeix en el Comtat llatí de Trípoli al que passa a pertànyer aquella altra de Tortosa.

Finalment el Comtat es cedeix a Ramon IV de Tolosa, que també assumeix el títol de comte de Mont Pelegrí pel lloc on féu erigir una fortalesa pels pelegrins de Terra Santa (en les immediacions de la ciutat de Trípoli) $)^{5}$.

A Ramon IV el succeeix als seus dos Comtats de Tolosa i de Trípoli el seu fill Bertran I de Sant Gelí, l'any 1105. El nou comte posa el Comtat de Trípoli sota la sobirania del rei Balduí II de Jerusalem ${ }^{6}$.

Mort Bertran, el 1112 l'hereta a Trípoli el seu fill Ponç I, que finalment reconeix com a príncep sobirà al d'Antioquia. El 1137 assumeix el Comtat el fill de l'anterior, Ramon II, i després el d'aquest el 1152 com Ramon III. Aquest és l'últim comte tolosà de Trípoli, doncs mor sense descendència i el seu domini passa definitivament al príncep d'Antioquia ${ }^{7}$.

\section{EL BISBAT SIRIÀ DE TORTOSA}

Ja a la ciutat de Tortosa s'erigeix un Bisbat, que depèn eclesiàsticament del Patriarcat d'Antioquia, amb la seva catedral dedicada a Nostra Senyora construïda el mateix s. XII.

I en data indeterminada però que podem situar entre 1147 i 1152 , la ciutat és arrasada i la catedral saquejada pels turcs. Per això l'Orde del Temple demana al comte Ramon II de Trípoli llicència per a poder construirhi un nou castell (segurament també en destruïren un d'anterior), a fi de que aquella Milícia es pugui ocupar de la seguretat i defensa de la ciutat i de la seva Església.

El comte amb el consentiment del seu fill (el futur Ramon III) i la seva cúria accedeixen a la petició del Temple, i així ho traslladen al bisbe

\footnotetext{
${ }^{5} \mathrm{AAVV}$, Recueil, pp. 149-159.

${ }^{6}$ De fet Jerusalem s'encomana a Godofred de Bouillón, que no accepta el títol de rei sinó el d'"Advocatus Sancti Sepulchri", segurament per reconèixer la superior autoritat del pontífex de Roma; però el seu germà Balduí, comte d'Edesa, el succeeix i es proclama rei (PORTELA ob. cit., pp. 189-190). Balduí és consagrat el 1101 pel patriarca de Jerusalem (AAVV, Recueil, p. 149).

${ }^{7}$ Nota 3. El primer príncep d'Antioquia és Bohemund de Tarento, després de disputar-s'ho precisament amb Ramon IV de Tolosa (PORTELA, ob. cit., p. 189).
} 
Guillem de Tortosa i al seu Capítol de canonges, que ho accepten a condició de pactar sobre els drets eclesiàstics dels delmes i de les parròquies que el Temple estableixi al Bisbat. Aquesta concòrdia o pacte se signa entre el bisbe Guillem de Tortosa i fra Everard de Barres, mestre de l'Orde del Temple, en un data que desconeixem amb exactitud però que serà entre els anys indicats de 1147 (quan fra Everard de Barres assumeix el càrrec de mestre de l'Orde) ${ }^{8}$ i 1152 (any de la mort de Ramon II).

Afegim que per la part del Bisbat, amb el bisbe signa la concòrdia com a testimoni un canonge (Ramon Fort), mentre que en la seva confirmació de 1156 n'intervenen dos (Oferi i Filibert).

\section{LA CÚRIA DEL COMTE DE TRÍPOLI}

El document en qüestió ens aporta dades interessants sobre la cúria o cort del comte i els seus oficials, amb una organització i unes funcions no dubtem que idèntiques a les de la cúria comtal de Tolosa.

Especial significació té al nostre entendre la participació en ella de magnats dedicats al comerç i a la indústria ja a mitjan s. XII. Efectivament, el permís que es dona a l'Orde del Temple perquè pugui construir la nova fortalesa el concedeix el comte amb la seva cúria de baronibus ac burguensibus aliisque quam pluribus, alguns dels quals signen la concòrdia amb el bisbe de Tortosa i un canonge de la Seu9. L'acte compta també amb el consentiment del fill del comte, Ramon (futur Ramon III de Trípoli).

Precisament entre els burgesos que signen el document com a testimonis apareix un Ramon Català, i encara hi ha un Ponç Català que és sagristà de l'Orde de l'Hospital també present al Comtat ${ }^{10}$. Altres testimo-

\footnotetext{
${ }^{8}$ Fra Everard de Barres succeeix com a mestre de l'Orde el gener de 1147 a fra Robert de Caon (Josep M. SANS TRAVÉ, Els templers catalans, de la rosa a la creu, Lleida, 1996, p. 91).

${ }^{9}$ I hem d'afegir que com la Cúria comtal de Barcelona del s. XII, bé que aquesta està integrada per barons $\mathrm{i}$ no hi són els burgesos. La Cúria barcelonesa està integrada pels "principes, episcopi, abbates, comites, vicecomites, comitores, vasvessores, philosophi et sapientes atque judices" [Jesús FERNÁNDEZ VILADRICH, Notas en torno a las Asambleas condales en la Catalunya de la Alta Edad Media, "Estudis Històrics i Documents dels Arxius de Protocols", X (1982), pp. 31 i ss.].

${ }^{10}$ Aquests Català potser són parents d'altre Pere Català que intervé en la Cort comtal de Barcelona l'any 1169 quan Alfons I rep un préstec de l'Orde del Temple de 5.000 morabatins (Josep SERRANo DAURA, El conflicte catalanoaragonès pel territori de la Ribera d'Ebre i de la Terra Alta, en els segles XIII i XIV, Ascó, 1997, p. 45).
} 
nis són curiosament dos cavallers membres de famílies vinculades a la Casa Comtal de Barcelona: Albert de Cabrera i Pere de Castellnou.

I també intervenen un vescomte, un mariscal, un conseller degà i un magister notarius (que tal vegada deu ser el cap de la Cancelleria comtal) ${ }^{11}$.

\section{LA CONCÒRDIA ENTRE EL BISBAT SIRIÀ DE TORTOSA I L'ORDE DEL TEMPLE}

D'aquesta manera en una data indeterminada però que es pot situar entre 1147 i 1152, el bisbe Guillem de Tortosa i el mestre de l'Orde del Temple, fra Everard de Barres, signen una concòrdia relativa bàsicament a la construcció d'un castell de l'Orde en aquella ciutat, al repartiment dels delmes que es recapten al Bisbat $i$ als drets dels cavallers templers sobre les parròquies que edifiquin en els seus dominis ${ }^{12}$.

És de destacar que en la datació del document es pren com a referència el sistema lunar (indictione $V$ ciclo decilunio -... XVIII), com és habitual en la documentació oficial del Comtat de Tolosa i del Regne franc; i per la seva influència també a Catalunya, doncs s'hi aplica sobretot en la documentació de l'Alta Edat Mitjana.

\section{a) El contingut de la concòrdia:}

El document té dues parts.

1. Sobre la construcció d'un castell per l'Orde del Temple:

El document en la seva primera part es refereix a una recent incursió turca, en la que s'ha incendiat $\mathrm{i}$ cremat la ciutat $\mathrm{i}$ profanat les esglésies $\mathrm{i}$ altres llocs de culte; s'assenyala que la ciutat havia quedat destruïda $\mathrm{i}$ despoblada. Precisament per aquests fets i per a defensar-la a ella i a la seva Església de nous atacs, l'Orde del Temple ha demanat i obtingut del comte

\footnotetext{
"Tots els càrrecs els ocupen oficials llenguadocians; i és evident que la Cort o Cúria comtal de Trípoli està organitzada com la de Tolosa. Pel que fa al "magistre notarius", cal destacar que precisament al Llenguadoc ja el s. XII s'introdueix la figura del notari com fedatari públic (més aviat que en altres territoris, alguns vinculats a Tolosa com són els comtats catalans) (José BONO, Historia del derecho notarial español, Madrid, 1979, pp. 107-108).

${ }^{12} \mathrm{El}$ document es troba a l'Archivo Histórico Nacional de Madrid (=AHN) i el publiquem com Apèndix del present article.
} 
Ramon II i de la seva cúria de baronibus ac burguensibus la llicència per a edificar un nou castell a la ciutat ${ }^{13}$.

El bisbe Guillem prèvia deliberació amb el Capítol de la Seu, decideix cedir al Temple un terreny al barri burgès de la ciutat prop del Portal de Santa Helena, tocant a la casa de Guillem de Tiberíades, perquè edifiqui el castell. A més el Bisbat eximeix de tot tribut l'Orde en raó de l'església que construeixi en el seu castell (consistia en la cinquena part dels drets que n'obtingués i que corresponien a la Seu per cessió comtal atorgada el seu dia sobre totes les esglésies de la ciutat).

2. Pel que fa als delmes i les esglésies parroquials en els dominis de l'Orde:

Com a conseqüència dels pactes anteriors es reconeixen com del Temple les esglésies que l'Orde construeixi en els seus castells i en tots els seus dominis presents i futurs en la circumscripció del Bisbat, quedant exempts de tot dret episcopal.

Quant als delmes que es recaptin als dominis de l'Orde s'assenyala que en principi s'han de repartir per meitats entre el Temple i el Bisbat. I s'afegeixen unes excepcions:

-Ni el Bisbat ni el Temple satisfaran delmes per les collites obtingudes i pels ramats criats en terres privatives d'un i de l'altre, fent menció especial a les sínies de Castellblanc que són del Temple i a les de Marraclea que pertanyen al Bisbat.

-L'Orde tampoc pagarà res pels guanys que obtingui en les seves expedicions (militars).

S'afegeix que aquest mateix tracte es farà amb l'Orde de l'Hospital, que ja deu està establert al mateix Bisbat; precisament se cita al mestre de l'Orde, Ramon, i justament un testimoni de la concòrdia és el sagristà hospitaler Ponç Català.

b) Acceptació i confirmació dels pactes:

Per últim, ambdues parts juren els pactes anteriors conforme els mantindran i respondran d'ells davant de tercers, excepte del papa i del

\footnotetext{
${ }^{13} \mathrm{El}$ comte és assistit per la seva Cúria, i les decisions pel que sembla es prenen conjuntament; cal destacar el fet que en ella junt amb els barons o noblesa comtal hi ha burgesos representants dels mercaders, comerciants, industrials $\mathrm{i}$ altres similars que deuen realitzar ( $\mathrm{i}$ dirigir) les activitats econòmiques del Comtat)
} 
patriarca d'Antioquia en el cas del Bisbat i del patriarca de Jerusalem en el del Temple. Aquesta salvetat s'introdueix sens dubte per quant aquells són els superiors respectius de cada part i com a tals, en aquell moment, encara han d'aprovar la concòrdia (i en qualsevol cas poden modificar-la).

En un darrer apartat es recull la confirmació posterior del document de 1156, per part del nou gran mestre del Temple fra Filibert Bertran de Blancafort ${ }^{14}$ i per Ramon III nou comte de Trípoli; l'acte se celebra la festa de l'Apòstol Sant Bernabé del mes de juny de dit any. També hi intervenen canonges, oficials comtals i cavallers templers.

Ja aquesta confirmació, que inclou l'acte o concòrdia inicial, es autenticada per un mestre de notaris o cap de la Cancelleria comtal tot i que el document el redacta un sacerdot magistri capellanus.

${ }^{14}$ Fra Filibert Bertran de Blancafort és mestre de l'Orde del Temple des de 1156 (substituint a fra Everard de Barres), i l'any 1176 el trobem a la Tortosa catalana (Joaquim MIRET I SANS, Les cases de templers $i$ hospitalers en Catalunya, Barcelona, 1910, pp. 91 i 182). 


\begin{abstract}
APÈNDIX
$1147 / 1152$

Pactes $i$ concòrdia entre el bisbe Guillem i el Capítol de la Seu de Tortosa de Síria, d'una part, i fra Everard de Barres gran mestre de l'Orde del Temple, de l'altra, autoritzant l'Orde a construir un nou castell a la ciutat i fixant el repartiment entre ambdues parts dels delmes i altres drets parroquials sobre les esglésies que l'Orde tingui al Bisbat.

[A] Original, perdut.

[B] Trasllat d'[A] fet l'11 de juny de 1156 per l'escrivà Azo 'i autoritzat per Sanaric, mestre de notaris.

[C] Trasllat de [B] fet per Joan Pellicer, notari d'Ascó d'autoritat apostòlica a mitjan s. XVI (a l'AHN, Secció d'Ordes Militars, Llibre núm. 1750 C -sig. ant. Encomienda de Azcón, Cabreo núm. 61, doc. núm. 56/1-).
\end{abstract}

In nomine sancte et individue Trinitati, Patris et Filli et Spiritu Sancti, amen. Ec est scriptura privilegii pacis et concordie qui facta est inter Willermus, Dei misericordia Tortosanum episcopus, et Ebrordum, eiusdem gratia Templi magistrum, et predicte ecclesie, canonicos et Templi fratres venerandos, de ecclesiis et decimis ipsius Episcopatus et de constructione novi castri in urbe, et de pontificali dignitate cum parrochia sicut inferius est scriptum.

Pateat, igitur, cunctis legentibus, tam presentibus quam futuris, quod civitas Tortossa, a turis capta et conbusta misserabiliter, remansit deserta et destructa et, quod est gravius, altaribus postratis, loca sancta inyquis profanationibus prodi dolor fuerunt contaminata. Qua propter preelibatus episcopus Graufredus, comunicato sibi suo Capitulo cum domino Raymundo comite tripolitano, Pontii çomites fillio, necnon sue Curie baronibus ac burguensibus aliisque quam pluribus Deum timentibus venerabilem magistrum Ebrordum nomine fratresque suos deprecatus est ut in eadem urbe, pro amore Dei sancteque cristianitatis, facerent novum castrum ad inhabitandum ut predictus episcopus suique succesores et homines in eadem urbe comorantes essent securiores et Ecclesia Sancte Dei genitricis semperque Virginis Marie tutius teneatur et edecantetur et, ut justum est, honestius ibi Deo serviatur. Cuius petitioni magister et fratres assensum prevuerunt; itaque ad aiutorium novi castri construendi, predictus episcopus Willermus cum suo Capitulo donat magistro Ebrordo venerabili suisque fratribus ipsam divisionem terre quam ibi episcopus habebat, in qua habitabant burguenses ab introitu parte usque ad domum Willermi de Tiberiade, et 
undique pervenit ad portam Sancte Elene, sublato inde cuncto edificio lapidum et lignorum ad partes episcopi. Ista namque divissio de dono et parte episcopi fuit: reliqua vero pars circunquaque de donatione predicti comitis fuit omnes vero ecclesie que in eadem urbe sunt aut fuerint vel foris in portu excepta propria fratrum Templi capella castri Tortosse erunt ecclesie et episcopi cum parrochia illa, vero ecclesie que in castris ubi fratres Templi habitandum fuerint ipsorum erunt libere et absolute cum omni parrochiali jure et omnes alie ecclessie totius episcopatus ipsorum erunt excepto marzaelea (...) et exert (?) et colea et castro novo, et rato et lato, tamen si ex prenominatis castris aliqua in eorum dominius venerint, cum parrochiis ipsorum erunt et ecclesie denique omnes decime totius episcopatus, excepta decima propii laboris episcopi et canonicorum, que sua propia erit, et excepta decima propii labores fratrum Templi, que similiter propia erit ipsorum fratrum, et exceptis illis lucris que in expeditionibus facient ubique ea facere contingerit, et exceptis minutis decimis animalium suorum et ortorum, que ibidem ipsorum fratrum propie remanebunt.

Omnes alie dico ipsius episcopi et canonicorum et magistri fratrumque suorum comunes erunt nisi in trato in quo prenominatus episcopus fecit donationem magistro Raymundo fratribusque Ospitalis, scilicet, decimam labores eorum et rote et medietatem aliarum decimarum.

Omnes vero redditus quos episcopus et canonici (h)abebunt de suis villanis et militibus decimabuntur qui debent decimari; similiter omnes redditus quos habebit magister et fratres de suis villanis et militibus decimabuntur qui debent decimari istorum omnium, una medietas erit ecclessie et episcopi, altera vero medietas erit magistri fatrumque suorum, excepta rota de Castroalbo que magistri et fratrum erit, et excepta rota de Morraclea que erit sedis tertossane et episcopi.

Propter hoc donum et concordiam superius descriptam sucepit episcopus Willermus cum canonicis suis magistrum et fratres in sua fide et dileccione suaque jura manutere et defendere contra omnes homines pro fidem certam sine inganno, excepto domino papa et patriarca antiocheno. Similiter venerabilis magister Ebrordus suique fratres susceperunt ecclessiam Tortossane sedis et episcopum Willermum necnon canonicos eius in sua fide et dilectione suaque iura manutenere et defendere contra omnes homines pro fidem certam sine inganno, excepto domino papa et patriarca iherosolimitano.

Hec igitur acta sunt et ex utraque parte sanita et omni scrupulo remoto veraciter concessa, salvo tamen iure utroque episcopi videlicet Tortossani et ecclessie et canonicorum set magistri et fratrum Templi similiter.

Huius rei testes legitimi suscribuntur: Willermus, Tripolitanus episcopus; Florencius, preceptor Tripolitanus; Raymundus, Tripolitanus comes, Pontii comiti filius, in cuius presentia hec facta sunt. Arnaldus de Cerest, contabularius Tripolis; Willermus Cimbriatus; Willermus Porcelletus; Willermus de Lunel, marescaltus; Ugo, sine sensu (sic); Silvius Robberti; Arbertus de Cabreria; Willermus Ramoardi 
Ramoradus; Bertranus de Muntpercos; Willermus, vicecomes Tripolis; Cassianus Ugo de Lirimaco; Jocelinus de Chaminuz; Lipinus de Vinols; Gonfridus de Sydone; Willermus de Cornual; Poncius de Ciura; Petrus de Munferrez; Willermus Rolandi; Raymundus Lamberti; Raymundus Arnaldi; Raymundus Catalanis; Petrus de Sancto Germano; Petrus Galie; Bonetus Maurus; Petrus de Castronovo; Raymundus Fortis, canonici Tortossani; Willermus Hugonis; Pontius Catalanus, sacristes Iherosolimitani.

Omnes subscripti testes sunt prime donationis et concessionis que facta est in tempore Raymundi comitis fillii Pontii, assensu Raymundi fillii sui, Ebrordo de Barris, Militum Templi magistro tunc temporis, existente post mortem vero prefati comitis, Raymundo, fillio eius, comitatum tenentem et predicte donationi omni modum assensum presente. Et Bertranio de Blancafort, Militie Templi magistro existente, eadem donatio apud Tripolini, mense junio, in solemnitate Sancti Bernabe apostoli, coram subscriptis testibus (...) (?) confirmata est et Tortosani episcopi sigilli autoritate munita canonici Tortossani Oferius et Filicherius; Raymundus, comes Tripolles; Arnaldus de Crestio constabularius Tripolli; Willermus Delmello, Tripolli marescalto; Willermus Porcelletus, salamantius; Facianus Enstorgius; Demmerat Bigerius. Burgenses: Pontius de Ciura; Petrus Girardi; Bertrandus Girardi; Willermus Isnellus; Raymundus Catalanus.

Confirmantes: Petrus Pasquelis; Aymericus Velocus; Petrus de Sancto Germano. Ex fratribus Templi: due capellani, Salio et Vernerius; magister Filibert Bertranuus de Blancefort; frater Roddolfus Depatinges; frater Ugo de Chaortin; frater Robertus Danis; frater Bonetus; frater Gaufrerius Cocherellus; frater Radulfus Demeheron; Radulfus Carnocensis, decanus morosii conselarius Tripolitanus.

Sanaricus, magistri notarius. Azo, magistri capellanus, qui hoc scripsit privilegium.

Actum est autem hoc anno Incarnationis Domini Nostri Iesuchristi MCLVI indictione $\mathrm{V}$ ciclo decilunio (..) XVIII.

\section{RÉSUMÉ}

L'année 1101 les croisés chrétiens conquèrent la ville de Constantine (à l'actuelle Syrie), ils changent sa denomination pour la de Tourtouse (comme autre ville catalane alors sous la domination musulmane), s'élève à siège épiscopal et s'intègre au Comté latin de Tripoli (aujourd'hui au Liban), que appartient au comte de Toulouse de Languedoc. À la mi du XII ${ }^{\mathrm{e}}$ siècle, les turcs la détruirent complètement, et pour assurer sa défense, le comte de Tripoli avec l'êveque autorisent l'Ordre du Temple la construction d'une nouvelle fortification à Tourtouse, avec des pactes sur des divers et reciproques droits économiques écclesiastiques. Le document que les recueille nous informe aussi sur l'organization politique du Comté de 
Tripoli, et de l'existence là d'une importante communauté bourgeoise, laquelle participe dans la cour comtale.

\section{SUMMARY}

In the 1101 the Christian Croats conquered the city of Constantina (nowadays Siria). Constantina changed its name for Tortosa (the same name as other Catalan city then under the Muslim control, Tortosa became the Episcopal see and joined the Latin County of Tripoli (nowadays Lebanon), ceded to the Tolosa Count of Languedoc. In the twelve century Turks desolated it; the Tripoli's Count and the Tortosa's Bishop allowed the Temple's Order to build a new fortification through several deals about the different and reciprocal ecclesiastical economical rights. We can find information about the political organization in the "County of Tripoli's document", where these rights are collected, and also about the existence of one important bourgeois community who participated in the Count's Curia. 